\title{
Lettres d'une Péruvienne, édition présentée, établie et annotée par Jonathan Mallison
}

\section{Irene Panighetti}

\section{Q OpenEdition}

1 Journals

\section{Edizione digitale}

URL: https://journals.openedition.org/studifrancesi/40738

DOI: 10.4000/studifrancesi.40738

ISSN: 2421-5856

\section{Editore}

Rosenberg \& Sellier

\section{Edizione cartacea}

Data di pubblicazione: 1 juillet 2004

Paginazione: 196-197

ISSN: 0039-2944

\section{Notizia bibliografica digitale}

Irene Panighetti, «Lettres d'une Péruvienne, édition présentée, établie et annotée par Jonathan

Mallison», Studi Francesi [Online], 142 (XLVIII | I) | 2004, online dal 30 novembre 2015, consultato il 09 septembre 2021. URL: http://journals.openedition.org/studifrancesi/40738 ; DOI: https://doi.org/

10.4000/studifrancesi.40738

Questo documento è stato generato automaticamente il 9 septembre 2021.

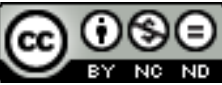

Studi Francesi è distribuita con Licenza Creative Commons Attribuzione - Non commerciale - Non opere derivate 4.0 Internazionale. 


\title{
Lettres d'une Péruvienne, édition présentée, établie et annotée par Jonathan Mallison
}

\author{
Irene Panighetti
}

\section{NOTIZIA}

Lettres d'une Péruvienne, édition présentée, établie et annotée par Jonathan MALLISON, Oxford, Voltaire Foundation, 2002, pp. 362.

1 Jonathan Mallison propone una nuova edizione critica di uno dei romanzi più diffusi nella Francia del Settecento. Egli utilizza come testo base l'edizione del 1752 delle Lettres d'une Péruvienne di Françoise de Graffigny, adottando semplici e chiari criteri editoriali: sulla base di interventi correttivi attuati già dalla stessa autrice del romanzo in due pagine di errata poste in appendice a qualche esemplare dell'edizione del 1752, Jonathan Mallison corregge venti errori del suo testo base; modernizza l'ortografia e certi usi grammaticali, regolarizza la punteggiatura e alcune costruzioni sintattiche. In apparato sono poste le varianti offerte dal testo della prima edizione del 1747, mentre nelle note sono fornite utili informazioni di carattere storico, linguistico e culturale.

L'edizione critica del testo delle Lettres d'une Péruvienne è arricchita da un dossier finale che permette di inserire il romanzo nel contesto storico in cui prese forma: ecco quindi che, al fine di rendere l'idea della ricezione dell'epoca delle Lettres d'une Péruvienne, Jonathan Mallison riporta diciotto scritti critici, siano essi resoconti giornalistici, lettere o reazioni di vario genere; tra essi spiccano per la notorietà dei loro autori, i pareri di Joseph de la Porte, di Antoine Sabatier de Castres e del marchese de Sade, oltre alle recensioni del «Mercure de France» e del «Journal de Trévoux». In fine, per documentare il successo riscosso dal romanzo, sono riportati estratti di qualche suite delle Lettres d'une Péruvienne e un adattamento teatrale del 1754. 
Oltre a fornire i mezzi per un'adeguata contestualizzazione del testo, Jonathan Mallison offre anche gli strumenti preparatori per affrontare al meglio la lettura: in una introduzione perfettamente riuscita, egli traccia un breve profilo biografico di Françoise de Graffigny, utile poi per riuscire a stabilire il grado di autobiografismo delle Lettres d'une Péruvienne; in proposito lo studioso anglosassone evidenzia come il romanzo sorpassi i confini dell'autobiografia, arrivando a costituire un testo particolarmente complesso e provocatore. Complesso in quanto si tratta di un sapiente intreccio di piani narrativi, di stili, di punti di vista, di tradizioni letterarie e di contesti culturali. Provocatorio poiché portatore di un messaggio anticonvenzionale, che si discosta dai canoni estetici e morali dell'epoca. In particolare è Zilia, la protagonista del romanzo, a farsi portavoce di questa presa di distanza dalle tradizioni. Secondo Jonathan Mallison le Lettres d'une Péruvienne rappresentano un Bildungsroman con una forte connotazione critica nei confronti della cultura e della società francese del Settecento: Zilia infatti percorre un cammino formativo che le permette di diventare una donna cosciente di sé e del proprio valore, in grado non solo di condurre una vita autonoma da ogni tipo di tutela maschile, ma capace anche di proporre uno sguardo critico verso ciò che la circonda. Per bocca di Zilia insomma, attraverso il paragone tra Perù e Francia, Françoise de Graffigny esprime un giudizio severo sulla superbia dei Francesi, che si credono il popolo migliore del mondo, così come critica lo stato di minorità in cui viene relegata la donna francese. Ancora, Zilia non solo è coscienza critica dell'altro da sé, della società dell'Ancien Régime, come potevano esserlo i persiani di Montesquieu: ella è anche una fine philosophe, che mette in discussione la sua propria cultura, le sue origini e tradizioni, il suo stesso essere, scoprendo che la verità non è monopolio di nessun paese, di nessun essere umano. Le Lettres d'une Péruvienne non prospettano ricette morali nè regole da seguire, bensì problematiche e spunti di riflessione. Questa, secondo Jonathan Mallison, la particolarità e l'originalità del romanzo, questo il massimo valore di un testo che evoca tensioni, equilibri fragili, tematiche affascinanti proprio per la loro apertura; ed è per questi motivi che le Lettres d'une Péruvienne suscitano ancora oggi intenso interesse. 